\title{
Political Competition And Campaign Contributions
}

\author{
Anna Dodonova, University of Ottowa
}

Yuri Khoroshilov, (Email: khoroshilov@mangement.uottawa.ca), University of Ottowa

\begin{abstract}
This paper presents a theoretical model of political competition that can explain the positive correlation between money spent by a political party on the election campaign and the number of votes received. The model does not assume that money can be used to fool voters or to buy votes. It shows that such correlation arises because of the existence of unobservable factors that affect both campaign spending and the result of the campaign. It analyzes how wealth inequality among political parties and the costs of information dissemination affect the choice of political platforms and amounts of money spent by each party and shows that all parties have incentives to spend money on the election campaign.
\end{abstract}

\section{PART 1: INTRODUCTION}

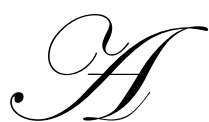

11 economic activities are heavily influenced by actions of individuals and bodies whom we elect. That is why it is very important to have a good economic model that describes electoral competition and the influence of different factors (such as voters' welfare, pressure groups activities, politician's private benefit) on the policies pursued by an incumbent politician.

It is well known that political parties spend a lot of money during election campaigns. Since people vote for the best (from their point of view) party, each party may decide to spend some money in order to convince voters that it is better than the rival parties are (TV commercials, public speeches, door-to-door propaganda, etc.). Baron (1989) and Grossman and Helpman (1996) provide an explanation why office-seeking politicians might want to sacrifice their political platforms in order to raise larger campaign contributions from the interest groups. They argue that a politician faces an implicit tradeoff between getting more votes cast by informed voters (in the case when she chooses the first-best political platform) and receiving larger campaign contributions that could help her to persuade uninformed voters (in the case when she chooses a platform that is favorable to one of the interest groups). In particular, they assume that campaign spending raises votes cast by uninformed voters directly. However, if voters cannot be fooled and if there is only one "best" party for the marginal voter, then it remains puzzling why each party is ready to spend money on the election campaign and why political parties choose distinct platforms when the marginal voter theory predicts that their platforms should be similar. Finally, since money is so important in the election campaign, one may be interest in how political platforms depend on the wealth inequality in a society?

In this paper we provide an answer to these three questions by developing a model that explains the observable behavior of rational voters. The existing voting theories cannot provide a good explanation why money spent on the election campaign by a political party is positively correlated with number of votes this political party receives $^{1}$ when all voters are rational. Poters, Sloof and Van Winden (1997) and Prat (1999) explain this fact by considering a signaling game that takes place between political parties and voters. In their models the only informative signal about characteristics of a party is the amount of money it spends on the election campaign. The disadvantages of this approach are that such models require a lot of intelligence from voters, allow multiple equilibria, and ignore the fact that voters can learn a great deal of information directly from the campaign agitation. Austen-Smith (1987)

\footnotetext{
${ }^{1}$ See Abramovich (1988), Pattie, Johnston, and Fieldhouse (1995), Nagler (1992), Palda and Palda (1998), for the empirical studies of how money spent during the election campaign affects the results of elections.
} 
assumes that campaign spending is not just "money burning" but helps to bring information to the voters. He assumes that voters are risk averse over the choice of political platforms. As a result, a politician who makes her platform clear to the voters has a better chance of winning the election. This approach is more realistic than the ones developed by Poters, Sloof, and Van Winden (1977) and Prat (1999), but requires a great deal of voters' risk-aversion and still can not explain why political parties spend so much money on the character debates.

Our paper presents an alternative answer to the question why there is a positive correlation between the amount of money spent on the election campaign and the probability of winning. Our approach is based on the assumption that there are unobservable factors (i.e., qualitative characteristics of political parties) that positively affect all people in the society. As a result each party needs to spend money to make voters aware of the differences in factors which make it looks better than the opponents. A party that has a greater comparative advantage in the majority of these factors will be willing to spend more money to advertise them and also has a larger change of winning the elections. Therefore, one cannot conclude that money raise votes but can conclude that money are positively correlated with votes. Our model not only proposes an answer to the question "Why money raise votes?" but also allows one to analyze how wealth inequality and the cost of information dissimilation affect the choice of political platforms and the amount of money spend on the election campaign. It predicts that political platforms of two major parties will be more distinct from each other in developing countries and in the countries where the financial resources of political parties are unequal. It also predicts that political parties will spent more money (as a fraction of GDP) in developed countries and in countries where the financial resources of political parties are unequal.

The model presented in this paper follows the line of "pressure groups" approach started by Stigler (1971), Peltzman (1976) and Becker (1983). A classic analysis in this tradition seeks to understand of how pressure groups influence election campaign and actions of incumbent politicians. Bernheim and Whinston (1986) consider the influence process as a "menu auction". Based on their model, Grossman and Helpman (1996) construct a model in which interest groups offer conditional transfer schedules to the policy maker. The policy maker then chooses policy to maximize her utility, which depends on transfers and the level of social welfare. Magee, Brock and Young (1989) and Hillman and Ursprung (1988) in contrast, consider competing political parties that announce policies that they are committed to implement if elected. After the announcement, pressure groups contribute resources to the party/politician that promises them the highest utility. All these models, however, assume that the announced compensation schemes and announced policies are binding while there are no institutions that can force politicians to implement their announced policies as well as can force pressure groups to contribute to politicians according to their "announced" compensation schemes. Institutions that could play this role cannot be legally established, in particular, because these compensation schemes might take form of bribes.

In this paper we continue to follow the "pressure groups" approach, but we do not make a distinction between pressure groups and politicians. In Part 2 we develop a model of political competition that can explain positive correlation between money and votes. We also look at the effects of income inequality on the choice of political platforms. At this stage we do not want to emphasize the fact that all political parties are willing to spend money during the election campaign. However, the model can be easily generalized to be able to explain this and Part 3 presents this generalization. Part 4 concludes.

\section{PART 2: BASIC MODEL}

Consider two political parties ("left" and "right ") with platforms $x_{l}$ and $x_{r}$ competing for an office. Platforms can be chosen from the segment $[0,1]$, i.e., the policy vector is one-dimensional. In addition to its platforms, each party is also characterized by its quality. Here, under quality we assume how efficiently the party can work in the office. Namely, different parties can have different abilities in the speed and quality of gathering information, as well as different abilities in analyzing this information and making decisions. So, the high quality of an incumbent party is beneficial for everybody in the economy.

The "left" party consists of identical people with ideal positions $w=0$ (ideal position is a political platform that gives a voter maximum possible expected utility). The "right" party consists of identical people with ideal 
positions $w=1$. One may think of these parties as some "political-financial" groups that derive utility out of their profits.

Assume that $\alpha$ voters have their ideal position $w=0, \beta$ voters have ideal position $w=1$ and the other (1- $\alpha$ $\beta$ ) identical voters may have any ideal $w \in[0,1]$ position (unknown to the other voters) with equal probability. If $\alpha<0.5$ and $\beta<0.5$, then the result of the election depends only on the decision of $(1-\alpha-\beta)$ median voters. Therefore, without loss of generality, we may assume $\alpha=\beta$.

Assume that the utility function of an individual with ideal position $\mathrm{w}$ is

$u=(1+a(w))\left(q-(w-x)^{2}\right)-m$

where $x$ is the platform of a party that will win the upcoming election; $q$ is its qualitative characteristic; $m$ is money spent by this individual on the election campaign; $a(w)$ shows how much this individual is interested in the outcome of the election. Thus, the utility of an individual depends positively on the winning party's qualitative characteristic, negatively on the difference between the individual's ideal policy (ideal position) and the winning party's platform, and negatively on the amount of money this individual spends on the election campaign. In what follows we assume that only political parties spend money on their campaign.

We assume that political parties represent wealthy individuals whose business is affected by the policy the winning party will implement. Thus, $1+a(w)$ can be viewed as the party's financial wealth, defined as the total financial wealth of individuals whose interests the party represents. Note that there is a distinction between financial wealth and amount of money collected as campaign contributions and spent on the campaign. For simplicity, we will assume that $a(w)=0$ for $w \neq 0$ and $a(0)=a \geq 0$.

Assume that the qualities characteristic between left and right parties is uniformly distributed with zero mean and the standard deviation that positively depends on the difference in the parties' platforms, i.e.,

$\bar{q}=\left(q_{l}-q_{r}\right) \sim U\left[\left(x_{l}-x_{r}\right)^{2},\left(x_{l}-x_{r}\right)^{2}\right]$

We assume the positive relationship between the standard deviation and the difference in political platforms because, e.g., in the case when the rival party wants to implement a platform that is very close to the previous incumbent's platform, this rival party has an example of how to pursue such a platform, and thus, there is less room for experimentation left. We also assume that the marginal standard deviation of $\bar{q}$ increases with the distance between the two platforms.

Political platforms, when chosen, are observed by all voters while the difference in the qualitative characteristic is known to the parties members only. ${ }^{2}$ Each party can spend some money in order to inform voters about the difference in the qualitative characteristic $\bar{q}=q_{l}-q_{r}$. We assume that if a party spends $\$ m$, then voters receive information about $\bar{q}$ with probability $\xi \sqrt{m}$, where $\xi$ is a parameter of "information technology". We also assume that medium voters are unaware of the financial wealth of any party, and, thus, believe that the strategies of both parties are symmetrical. As a result, if voters do not receive any information about $\bar{q}$, they believe that $E \bar{q}=0$.

\footnotetext{
${ }^{2}$ An alternative assumption could be that each party knows their own candidate well, but may not know more than a common voter about the characteristics of the other candidate. However, such assumption is less appealing since in reality political parties arguably have a better access to information than the common voters.
} 
The sequence of events is the following. First, both parties simultaneously choose their platforms. Then, the qualitative characteristics of parties are realized. Based on this information, each party decides how much money it is willing to spend on the election campaign. Finally, the election takes place.

To find a subgame perfect Nash equilibrium, one needs first to find the amount of money each party spends on its campaign as a function of the observed political platforms. Let us look at the left party first. The probability for the left party to win is equal to the ideal position of a voter who would be indifferent between the political parties. If voters do not receive information about $\bar{q}$, then the probability for the left party to win is $\frac{x_{l}+x_{r}}{2}$. If voters receive information about $\bar{q}$, then this probability is ${ }^{3}$

$$
w=\frac{x_{l}+x_{r}}{2}+\frac{\bar{q}}{2\left(x_{r}-x_{l}\right)} .
$$

Therefore, only one party is willing to spend money on the election campaign (if $\bar{q}>0$ then the left party spends some money, if $\bar{q}<0$ then the right party spends do so). Hence, when $\bar{q}>0$ and the left party spends $m_{l}$ dollars, the probability of its winning increases by $\xi \sqrt{m_{l}}\left(w-\frac{x_{l}+x_{r}}{2}\right)=\xi \sqrt{m_{l}} \frac{\bar{q}}{2\left(x_{r}-x_{l}\right)}$ and its expected utility increases by $\xi \sqrt{m_{l}}(1+a) \frac{\bar{q}}{2\left(x_{r}-x_{l}\right)}\left(\bar{q}-x_{l}^{2}+x_{r}^{2}\right)$.

Given the political platforms, the left party wants to maximize the expected gain of its members minus expenses on the campaign. Thus, if $\bar{q}>0$, the optimization program for the left party can be written as

$$
\underset{\left\{m_{l}\right\}}{\operatorname{Max}}\left[\xi \sqrt{m_{l}}(1+a) \frac{\bar{q}}{2\left(x_{r}-x_{l}\right)}\left(\bar{q}-x_{l}^{2}+x_{r}^{2}\right)-m_{l}\right] .
$$

Taking the first derivative of (4) leads to the First Order Condition (FOC)

$$
\sqrt{m_{l}}=\xi(1+a) \frac{\bar{q}\left(\bar{q}-x_{l}^{2}+x_{r}^{2}\right)}{4\left(x_{r}-x_{l}\right)} .
$$

Similarly, in the case when $\bar{q}<0$, the optimization problem for the right party leads to

$$
\sqrt{m_{r}}=\xi \frac{\bar{q}\left(\bar{q}-\left(1-x_{l}\right)^{2}+\left(1-x_{r}\right)^{2}\right)}{4\left(x_{r}-x_{l}\right)} .
$$

Equations (3), (5) and (6) imply that, in the case when a party's quality is higher than that of the rival party, the probability of winning positively depends on the amount of money spent by the party and on the party's quality. Therefore, the following Result is true:

\footnotetext{
${ }^{3}$ Note that w satisfies $q_{l}-\left(w-x_{l}\right)^{2}=q_{r}-\left(w-x_{r}\right)^{2}$.
} 


\section{RESULT}

Money spent on the election campaign and the probability of winning are positively correlated even if all voters are rational and cannot be fooled during the election campaign.

Taking the future campaign expenditures (5) and (6) into account, each party chooses its political platform in order to maximize the utility of its members. Thus, the equilibrium political platforms $x_{l}$ and $x_{r}$ can be found from:

$$
\left\{\begin{array}{l}
\underset{\left\{x_{l}\right\}}{\operatorname{ax}} E\left[u_{l}\left(x_{l}, x_{r}\right)\right] \\
\operatorname{Max}_{\left\{x_{r}\right\}} E\left[u_{r}\left(x_{l}, x_{r}\right)\right]
\end{array}\right.
$$

This system can be reduced (see Appendix) to the system of equations (8) and (9):

$$
\begin{aligned}
& 16(1+a)\left(-t^{2}+2 t y\right)+(1+a)^{2} \xi^{2}\left(-\frac{7}{10} y^{5}-\frac{11}{6} y^{4} t-\frac{4}{3} y^{3} t^{2}\right)+2(1+a) \xi^{2}\left(-\frac{17}{10} y^{5}-\frac{19}{6} y^{4}(1-t)+\frac{4}{3} y^{3} t(2-t)\right)=0 \\
& 16\left(-(2-t)^{2}+2 y(2-t)\right)+\xi^{2}\left(-\frac{7}{10} y^{5}-\frac{11}{6} y^{4}(2-t)-\frac{4}{3} y^{3}(2-t)^{2}\right)+2(1+a) \xi^{2}\left(-\frac{17}{10} y^{5}-\frac{19}{6} y^{4}(1-t)+\frac{4}{3} y^{3} t(2-t)\right)=0
\end{aligned}
$$

where $y=x_{r}-x_{l}$ and $t=x_{r}+x_{l}$.

Unfortunately, it is impossible to find a closed form solution for system (8)-(9). However, one can further simplify it by assuming $a=0$ (political parties have identical financial wealth) and examine the properties of the symmetrical equilibrium in which $\frac{1}{2}-x_{l}=x_{r}-\frac{1}{2}$. In the case of the symmetrical equilibrium we have $t=1$ and the system (8), (9) can be reduced to only one equation (10):

$$
16(2 y-1)+\xi^{2}\left(-\frac{41}{10} y^{5}-\frac{11}{6} y^{4}+\frac{4}{3} y^{3}\right)=0
$$

While equation (10) still does not have a closed form solution, it is easy to find the solution $y(\xi)$ numerically. The first very important result that follows from (10) is that political parties choose different political platforms: $x_{l} \neq x_{r}$

One can also find how the choice of equilibrium platforms is affected by the wealth inequality among political parties. By taking a full differential of (8) and (9), we can find derivatives $\frac{d x_{r}}{d a}$ and $\frac{d x_{l}}{d a}$ at point $a=0$. By analyzing these derivatives one can find that the following set of results is true:

(i) An increase in one party's financial wealth induces both political parties to take more radical (i.e., further from the centrists) platforms, i.e., $\frac{d x_{r}}{d a}>0$ and $\frac{d x_{l}}{d a}<0$. 
(ii) A political party with more financial assets chooses more radical platform than its opponent does, i.e., $\frac{d\left(x_{r}+x_{l}\right)}{d a}<0$.

(iii) An improvement in information technology reduce these abovestated effects of wealth inequality on the choice of political platforms, i.e., $\frac{d}{d \xi}\left(\frac{d x_{r}}{d a}\right)<0, \frac{d}{d \xi}\left(\frac{d x_{l}}{d a}\right)>0, \frac{d}{d \xi}\left(\frac{d\left(x_{r}+x_{l}\right)}{d a}\right)>0$.

Therefore, one can expect political parties in developing countries with poor information technology to take more distinct (from each other) positions than political parties in the developed countries do.

It is also interesting to look at the effects that wealth inequality and costs of information dissemination have on the amount of money spent by political parties on their campaigns. By solving (10) numerically and substituting $x_{l}$ and $x_{r}$ into (5) and (6) one can find that $\frac{d\left(m_{l}+m_{r}\right)}{d \xi}>0$, i.e., that the total amount of money spent on election campaign increase with the improvement in information technology. Thus, one can expect that in developed countries with relatively cheap communication facilities more money will be spent during the election campaign. Also, political parties will spend more (over time) as communication technologies become cheaper. This result is not as intuitive as it may appear because it is based only on the differences in communication technologies and not on the differences in income levels. In other words, the model predicts that the total expenditure on the election campaign in developed countries is higher (as a fraction of GDP) than it is in developing countries. It also predicts that, due to improved communication technology, campaign expenditures are higher in developing countries than they were in developed countries when developed countries had the same income level. The result that campaign expenditures (as a fraction of GDP) increase over time is also consistent with empirical evidence that nominal and real campaign expenditures increase over time. For example, in the U.S. the total spending by the two main political parties increased from $\$ 1,552.8$ million (federal dollars) in 1980s to $\$ 2,158.9$ million in $1990 \mathrm{~s}^{4}$

To find how money spent depend on the wealth inequality, on can solve (8) and (9) for $x_{l}$ and $x_{r}$ and substitute them into (5) and (6). By doing so one can find that $\frac{d\left(m_{l}\right)}{d a}>0$ and $\frac{d\left(m_{r}\right)}{d a}>0$, i.e., that an increase in one of the parties wealth that lead to the higher wealth inequality makes both parties willing to spend more on the campaign. One can also find that $\frac{d}{d \xi}\left(\frac{d\left(m_{l}+m_{r}\right)}{d a}\right)>0$, i.e., that cheaper information technology (higher $\xi$ ) leads to a larger effect of wealth inequality on the total amount of money spent on the election campaign. However, it is interesting to note that $\frac{d m_{l}}{d a}>\frac{d m_{r}}{d a}$ for small $\xi$ and $\frac{d m_{l}}{d a}<\frac{d m_{r}}{d a}$ for large $\xi$. The important implication of these results is that it implies that in countries with expensive information technology (e.g., developing countries) parties with more financial assets spend more on the election campaign than the other parties do. On the contrary, in countries with cheap information technologies (e.g., developed countries) political parties that have less financial assets spend more on the campaign than more wealthy parties do.

\section{PART 3: GENERALIZED MODEL: A VECTOR OF QUALITATIVE CHARACTERISTICS}

In Part 2 we assumed that quality characteristics of political parties are one-dimensional and one of the results that we received was that only the party with better quality spends money on its election campaign. In reality we see that all political parties are willing to spend money on campaign advertising. In these advertisements political

\footnotetext{
${ }^{4}$ Data is available from the Federal Election Commission (FEC).
} 
parties are trying to emphasize their advantages and not to talk about their "weak" sides. In order to describe this behavior of political parties we generalize our model in the following way.

Let $q^{l}=\left(q_{1}^{l}, q_{2}^{l}, \ldots, q_{n}^{l}\right), q^{r}=\left(q_{1}^{r}, q_{2}^{r}, \ldots, q_{n}^{r}\right)$ be vectors of qualitative characteristics (instead of just one-dimensional qualities) for the left and the right political parties correspondingly. As before, denote $\bar{q}=q^{l}-q^{r}$ (so, $\bar{q}$ is the vector of differences in qualitative characteristics) and $\bar{q}_{i} \sim U\left[-\left(x_{l}-x_{r}\right)^{2},\left(x_{l}-x_{r}\right)^{2}\right]$, where $\bar{q}_{i}$ is a $i$ 's element of vector $\bar{q}$ and all $\bar{q}_{i}$ s are independent on each other. Let the utility function of an individual with ideal position $w$ be $u=(1+a(w))\left(\frac{\sum_{i=1}^{n} q_{i}}{n}-(w-x)^{2}\right)-m$, where $x$ is the platform of an incumbent party, $q$ is a vector of its qualitative characteristics, $m$ is the amount of money spent by this individual on the campaign. Parameter $a(w)$ shows how much this individual is interested in the outcome of the election campaign. Information technology is the following. If a party spends $\$ m_{i}$ to inform voters about $\bar{q}_{i}$ voters receive this information with probability $\xi \sqrt{m_{i}}$. We also assume that each political party may advertise as many $\bar{q}_{i}$ as it wishes.

The analysis of this generalized model is similar to the analysis of the model in Part 2. Given the choice of platforms $x_{l}$ and $x_{r}$ each political party is willing to spend some money to advertise its advantages. The F.O.C. for the second period problem is given by:

if $\bar{q}_{i}>0$, then $\sqrt{m_{i}^{l}}=\xi(1+a) \frac{\bar{q}_{i} \times\left(\frac{\sum_{i=1}^{n} \bar{q}_{i}}{n}-x_{l}^{2}+x_{r}^{2}\right)}{4 n\left(x_{r}-x_{l}\right)}$ and $m_{i}^{r}=0$;

if $\bar{q}_{i}<0$, then $\sqrt{m_{i}^{r}}=\xi \frac{\bar{q}_{i} \times\left(\frac{\sum_{i=1}^{n} \bar{q}_{i}}{n}-\left(1-x_{l}\right)^{2}+\left(1-x_{r}\right)^{2}\right)}{4 n\left(x_{r}-x_{l}\right)}$ and $m_{i}^{l}=0$.

So, one can see that it is possible for both political parties to be willing to spend money during the election campaign. The probability that both parties spend money increases as $n$ increases (this probability is equal to $1-2^{1-n}$ ). One can also see that a party spends relatively more on advertising of those qualitative characteristics in which it has larger comparative advantage.

\section{PART 4: CONCLUSION}

This paper presents a model of political competition which is consistent with empirical evidence that money spent by political parties on the election campaign is positively correlated with votes these parties receive. The important feature of our model is an assumption that voters cannot be fooled, votes cannot be bought, and money cannot increase votes directly. We show that that there is no casual relationship between money spent by political 
parties and the results of the election campaign. We demonstrate that the positive correlation between those two values can arise because of the existence of some unobservable factors (e.g., quality characteristics of candidates) that affect the amounts of money spent on the campaign and the probability of winning in the same way.

We analyzed how wealth inequality between political parties and the cost of information dissemination affect the choice of political platforms, the total amount of money spent, and relative amount of money spent by each political party on the election campaign.

The model is consistent with empirical evidence that nominal and real campaign expenditures as a fraction of GDP increase over time. The model predicts that campaign expenditures as a fraction of GDP are higher in developed countries than they are in developing countries. However, due to improved communication technology, these expenditures are higher in developing countries than they were in developed countries when developed countries had the same income level. In the case of wealth inequality among political parties, more wealthy parties choose more radical platforms and less wealthy parties choose more centrist platforms. The model also predicts that more wealthy parties do not necessary spend more money on the election campaign than less wealthy parties do. For political parties with different financial wealth, the difference between their campaign expenditures depends on the level of communication technology in the country.

\section{APPENDIX}

$$
\begin{aligned}
& E\left[u_{l}\left(x_{l}, x_{r}\right)\right]=E\left[u_{l}\left(x_{l}, x_{r}\right) \mid \bar{q}>0\right] \cdot \operatorname{Pr}[\bar{q}>0]+E\left[u_{l}\left(x_{l}, x_{r}\right) \mid \bar{q}<0\right] \cdot \operatorname{Pr}[\bar{q}<0]= \\
& =\frac{1}{2} E\left[u_{l}\left(x_{l}, x_{r}\right) \mid \bar{q}>0\right]+\frac{1}{2} E\left[u_{l}\left(x_{l}, x_{r}\right) \mid \bar{q}<0\right]
\end{aligned}
$$

where

$$
\begin{aligned}
& {\left[u_{l}\left(x_{l}, x_{r}\right) \mid \bar{q}>0\right]=\left[\frac{x_{r}+x_{l}}{2}+\frac{\bar{q}^{2}\left(\bar{q}+x_{r}^{2}-x_{l}^{2}\right)(1+a)}{8\left(x_{r}-x_{l}\right)^{2}} \xi^{2}\right](1+a)\left(\bar{q}+x_{r}^{2}-x_{l}^{2}\right)+} \\
& +\left(q_{r}-x_{r}^{2}\right)(1+a)-\frac{\bar{q}^{2}\left(\bar{q}+x_{r}^{2}-x_{l}^{2}\right)^{2}(1+a)^{2}}{16\left(x_{r}-x_{l}\right)^{2}} \xi^{2}
\end{aligned}
$$

and

$$
\left[u_{l}\left(x_{l}, x_{r}\right) \mid \bar{q}<0\right]=\left[\frac{x_{r}+x_{l}}{2}+\frac{\bar{q}^{2}\left(\bar{q}+\left(1-x_{r}\right)^{2}-\left(1-x_{l}\right)^{2}\right)}{8\left(x_{r}-x_{l}\right)^{2}} \xi^{2}\right](1+a)\left(\bar{q}+x_{r}^{2}-x_{l}^{2}\right)+\left(q_{r}-x_{r}^{2}\right)(1+a)
$$

Thus, given $\bar{q} \sim U\left[-\left(x_{r}-x_{l}\right)^{2},\left(x_{r}-x_{l}\right)^{2}\right]$ one can find that

$$
E\left[u_{l}\left(x_{l}, x_{r}\right)\right]=(1+a) \frac{y t^{2}}{2}+\frac{(1+a)^{2} \xi^{2}}{32}\left(\frac{y^{6}}{5}+\frac{y^{5} t}{2}+\frac{y^{4} t^{2}}{3}\right)+\frac{(1+a) \xi^{2}}{16}\left(\frac{y^{6}}{5}+\frac{y^{5}(1-t)}{2}+\frac{y^{4} t(2-t)}{3}\right)
$$

where $y=x_{r}-x_{l}, t=x_{r}+x_{l}$. 
Therefore, the F.O.C. is

$$
\begin{aligned}
& 16(1+a)\left(-t^{2}+2 t y\right)+(1+a)^{2} \xi^{2}\left(-\frac{7}{10} y^{5}-\frac{11}{6} y^{4} t-\frac{4}{3} y^{3} t^{2}\right)+ \\
& +2(1+a) \xi^{2}\left(-\frac{17}{10} y^{5}-\frac{19}{6} y^{4}(1-t)+\frac{4}{3} y^{3} t(2-t)\right)=0
\end{aligned}
$$

Similar, for the right party we can receive

$$
\begin{aligned}
& 16\left(-(2-t)^{2}+2 y(2-t)\right)+\xi^{2}\left(-\frac{7}{10} y^{5}-\frac{11}{6} y^{4}(2-t)-\frac{4}{3} y^{3}(2-t)^{2}\right)+ \\
& +2(1+a) \xi^{2}\left(-\frac{17}{10} y^{5}-\frac{19}{6} y^{4}(1-t)+\frac{4}{3} y^{3} t(2-t)\right)=0
\end{aligned}
$$

\section{REFERENCES:}

1) Abramovich, A., 1988. Explaining Senate Election Outcomes. American Political Science Review 82. $385-$ 403

2) Austen-Smith, D., 1987. Interest Groups, Campaign Contributions, and Probabilistic Voting. Public Choice 54, 123-140.

3) Baron D., 1989. Service-Induced Campaign Contributions and the Electoral Equilibrium. Quarterly Journal of Economics 104, 45-72.

4) Becker, G., 1983. A Theory of Competition Among Pressure Groups for Political Influence. Quarterly Journal of Economics 98, 371-400.

5) Bernheim, B. and Whinston, M., 1986. Menu Auctions, Resource Allocation and Economic Influence. Quarterly Journal of Economics 101, 1-32.

6) Grossman, G. and Helpman, E., 1996. Electoral Competition and Special Interest Politics, Review of Economic Studies 63, 265-286

7) Hillman, A. and Ursprung, H., 1988. Domestic Politics, Foreign Interests, and International Trade Policy. American Economic Review 78, 729-745.

8) Magee, S., Brock, W., and Young, L., 1989. Black hole tariffs and endogenous policy theory: Political Economy in General Equilibrium. Cambridge, Cambridge University Press.

9) Nagler, J., 1992. Presidential Campaign Expenditures: Evidence on Allocations and Effects. Public-Choice 73, 319-333

10) Palda, F. and Palda, K., 1998. The Impact of Campaign Expenditures on Political Competition in the French Legislative Elections of 1993. Public-Choice 94, 157-174.

11) Pattie, J., Johnston, R., and Feildhouse, A., 1995. Winning the Local Vote: The Effectiveness of Constituency Campaign Spending in Great Britain, 1983-1992. American Political Science Review 89, 969983.

12) Peltzman, S., 1976. Toward a More General Theory of Regulation? Journal of Law and Economics 19, 211240 .

13) Prat, A., 1999. Campaign Spending with Office-Seeking Politicians, Rational Voters and Multiple Lobbies. Working Paper, CentER and Tilburg University.

14) Stigler, G., 1971. The Economic Theory of Regulation. Bell Journal of Economics and Management Science 2, 3-22. 


\section{NOTES}

